\title{
Ten minutes with Professor Helen McShane, Director, NIHR Oxford Biomedical Research Centre, Oxford University Hospitals NHS Foundation Trust
}

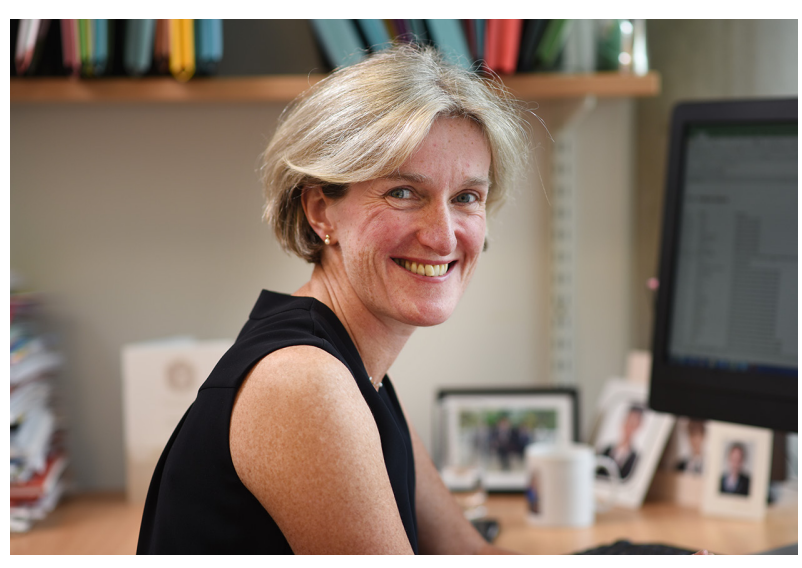

FIRST AND FOREMOST, ARE THERE ANY KEY LEADERSHIP MESSAGES YOU WANT TO GET OUT TO OUR READERSHIP?

Be authentic. Be yourself and develop a leadership style that is true to you. When things go wrong (as they will), you will revert to type under the stress. And if in so doing you reveal a very different leadership style to the one you have been affecting, you will lose the confidence of the teams around you. But if you are authentic from the start, then even in times of crisis, you will retain the trust of those you lead.

\section{TELL US A LITTLE BIT ABOUT YOUR LEADERSHIP ROLE AND} HOW IT IS CHANGING AS A RESULT OF THE PANDEMIC?

I have a number of leadership roles both within the university and externally. However, my main roles, and those which have come to the forefront during this pandemic, are first as the Director of the National Institute for Health Research (NIHR) Oxford Biomedical Research Centre (BRC), ${ }^{1}$ and second as Deputy Head of the Medical Sciences Division at the University of Oxford, with responsibility for translation (of laboratory research discoveries into clinical practice). As BRC Director, I am responsible for leading the scientific strategy and oversight of a $£ 114 \mathrm{~m}$ contract, from the NIHR to the Oxford University Hospitals NHS Foundation Trust (OUH Trust), to conduct translational research for patient benefit. Most of this funding is already preallocated to the 20 themes that make up our BRC, which are organised as four research 'clusters'.

One of the first things I did, when the scale of the pandemic became clear, was to work with colleagues leading the clusters to secure their agreement for us to reallocate that cluster funding for pump-priming COVID-19-related translational research. Using this funding, we have already funded six important COVID-19-related projects, and we still have some funding remaining. I am now working with the OUH Trust R\&D department to release some further funding from a different source for this pump-priming pot.

One of the challenges in times of crisis, particularly in large, highly devolved institutions, is communication. After the scale of the COVID-19-related clinical and translational research activity being undertaken - within both the university and the OUH Trust - became clear, I convened a clinical research prioritisation

\section{Biography}

Helen McShane is currently Director of the Oxford National Institute for Health Research Biomedical Research Centre; Professor of Vaccinology at Oxford University; Deputy Head (Translation and Personnel), Medical Sciences Division; and an Honorary Consultant Physician in Infectious Diseases. She was elected to be a fellow of the Academy of Medical Sciences in 2019.

Since 2001, she has been funded by the Wellcome Trust (as a Clinician Scientist and then two Senior Fellowships) to lead the tuberculosis (TB) vaccine research group at the University of Oxford. She specialised in HIV and Genito-Urinary Medicine and continues to practice as an HIV physician. She currently holds a Wellcome Trust Investigator Award. Her current research focus is on aerosol delivery of TB vaccines and the development of a controlled human infection model for TB. She continues to collaborate widely across the world including several longstanding collaborations with groups in Africa.

She has served as a member of WHO review groups many times, chaired Wellcome Trust funding panels and served as a member of the GLOBVAC (Global Health and Vaccination Research) board. She is currently on the Oxford University Innovation Board and a member of the Wellcome Science Strategy Advisory Committee.

group, which I co-chair with the NHS Director of R\&D. This group has representation from all stakeholders including respiratory physicians, intensivists, NHS R\&D, Infectious Diseases and the University Clinical Trials and Research Governance office, and now meets weekly to discuss and prioritise clinical research activities. This prioritisation is critical, given finite resources, both of staffing and infrastructure, and ultimately finite numbers of patients as well. It is absolutely crucial that people work together as a team in times like this, understanding that this enables much better quality research and better clinical operations as well. I now spend a significant proportion of my week on this work of clinical prioritisation, reviewing proposals, and working behind the scenes with various applicants and stakeholders, to ensure we do as much high-quality translational COVID-19 research as possible.

Overall, since the pandemic began, I have intensified my activities in establishing priorities, securing and allocating resources, and communicating and coordinating the outcomes.

\section{WHAT EVENTS IN YOUR PAST EXPERIENCE ARE MOST INFORMING YOUR LEADERSHIP IN THIS PANDEMIC?}

Some years ago, I led the design, execution and analysis of a large phase IIb clinical trial with a new tuberculosis $(\mathrm{TB})$ vaccine in $\sim 3000$ South African babies. ${ }^{2}$ This trial was the first of its kind anywhere in the world, and the stakes were high. There were a number of stakeholders involved in this work including universities (University of Oxford and the University of Cape Town), funders (The Wellcome Trust and The Gates Foundation) 
and industrial partners (Emergent BioSolutions and IDT). These different stakeholders had, at times, different perspectives, different priorities and different agendas. Leading this consortium for 5 years taught me the overwhelming importance of communication; of working with each of the stakeholders to ensure I understood what their needs were; and then of acting as a broker between different partners at times, to ensure everyone understood enough of each other's perspective to bring them together so we could all face the same way. The trial was completed successfully and published in a peer review, open access journal, 10 working days after I first saw the data. Transparency, and making the full trial dataset freely and openly available, was very important for the field, and is an important principle for science in general.

\section{WHAT ARE YOU FINDING THE BIGGEST CHALLENGES?}

Having tackled the challenge of facilitating and coordinating COVID-19 clinical research activity in Oxford, my next challenge flows from it. Colleagues are increasingly approaching me for advice and guidance with their plans and ideas. This is wonderful, and it is a privilege to be able to help them, signpost what they need, and so on, but this has resulted in a significant increase in email traffic which is increasingly difficult to manage effectively. In addition, there are many challenges with working from home with three teenagers in the house!

\section{ANY PARTICULAR SURPRISES?}

How many of the barriers to working efficiently and effectively melt away in a crisis. Only the real ones stay. And bureaucracy is minimised, as people are more able to focus on what is really needed and what is important. It is very refreshing, and I hope we can retain some of this perspective when the pandemic has passed.

\section{ARE YOU SEEING ANY BEHAVIOURS FROM COLLEAGUES THAT ENCOURAGE OR INSPIRE YOU?}

I am inspired daily by the very many colleagues I work with who are prepared to go way above and beyond for the bigger picture. Not for themselves but for the greater good.

\section{HOW ARE YOU MAINTAINING KINDNESS AND COMPASSION?}

I was attracted to medicine as a career (rather than law, which I was also considering) because fundamentally I am a people person. I like interacting with different people. And even now with my significant leadership responsibilities, I still see patients once a week. At the moment, these consultations are via the telephone. But they provide a very important reminder of how important the human touch is. How important that personal interaction is, even if it is now over Zoom. And how kindness, whether from a friend, a colleague or a stranger, can transform the moment and helps make the world a better place, evenor perhaps especially - at times of unprecedented global uncertainty. I always try and see the other perspective. I try and care about everything I do.

\section{ARE THERE ANY IDEAS OR READINGS THAT YOU FIND HELPFUL FOR INSPIRATION AND SUPPORT THAT YOU WOULD RECOMMEND TO OTHERS?}

I would love to say I read around the subject of leadership, as it is something that fascinates me. But sadly, with three teenagers and at least one full-time job, I barely get time to read anything. However, although I do not read regularly on this subject, I do often reflect on the outstanding leadership course, funded by the Wellcome Trust and lead by Deloitte, that I was fortunate enough to go on. One of the most memorable parts of this course was meeting some of the leaders they brought to talk to us. I will never forget two of them. A previous submarine commander talked about the importance of authenticity. And a previous president of Massachusetts Institute of Technology (MIT) talked about 'leadership as service' and 'putting ego aside, to create an environment which allows others to flourish'. That comment will stay with me forever, as my model of leadership to aspire to. And in a small way, this is what I hope I am doing at the moment; working to facilitate all the translational COVID-19-related research within the Medical Sciences Division, allowing others to be successful so patients can benefit.

\section{WHAT ARE YOU LOOKING FOR FROM YOUR LEADERS?}

Honesty, integrity, authenticity, transparency and humanity.

Helen McShane, ${ }^{1}$ Anthony Robert Berendt ${ }^{2}$

${ }^{1}$ NIHR Biomedical Research Centre, Oxford University, Oxford, UK

${ }^{2}$ Oxford, UK

\section{Correspondence to}

Dr Anthony Robert Berendt, Oxford, UK; a.berendt@ntlworld.com

Twitter Anthony Robert Berendt @tony_berendt

Funding The authors have not declared a specific grant for this research from any funding agency in the public, commercial or not-for-profit sectors.

Competing interests None declared.

Patient consent for publication Not required.

Provenance and peer review Not commissioned; internally peer reviewed.

Data availability statement No data are available.

(c) Author(s) (or their employer(s)) 2020. No commercial re-use. See rights and permissions. Published by BMJ.

$$
\text { Check for updates }
$$

To cite: McShane H, Berendt AR. BMJ Leader 2020;4:96-97.

Received 19 April 2020

Accepted 21 April 2020

Published Online First 11 May 2020

BMJ Leader 2020;4:96-97.

doi:10.1136/leader-2020-000268

\section{REFERENCES}

1 NIHR Oxford biomedical research centre, 2020. Available: https://oxfordbrc.nihr.ac.uk/

2 Tameris MD, Hatherill M, Landry BS, et al. Safety and efficacy of MVA85A, a new tuberculosis vaccine, in infants previously vaccinated with BCG: a randomised, placebocontrolled phase 2B trial. Lancet 2013;381:1021-8. 